\title{
Erratum to: Radiation Belt Storm Probes Ion Composition Experiment (RBSPICE)
}

\author{
D.G. Mitchell • L.J. Lanzerotti • C.K. Kim • M. Stokes • G. Ho • S. Cooper •
}

A. Ukhorskiy · J.W. Manweiler · S. Jaskulek · D.K. Haggerty • P. Brandt • M. Sitnov • K. Keika · J.R. Hayes · L.E. Brown · R.S. Gurnee · J.C. Hutcheson • K.S. Nelson • C.M. Hammock $\cdot$ N. Paschalidis $\cdot$ E. Rossano $\cdot$ S. Kerem

Published online: 11 June 2013

(C) Springer Science+Business Media Dordrecht 2013

\section{Erratum to: Space Sci Rev \\ DOI 10.1007/s11214-013-9965-x}

Unfortunately, the author C.M. Hammock was not included in the author group in the original published article. The author has now been added.

The online version of the original article can be found under doi:10.1007/s11214-013-9965-x.

D.G. Mitchell · C.K. Kim · M. Stokes · G. Ho · S. Cooper · A. Ukhorskiy · S. Jaskulek · D.K. Haggerty ·

P. Brandt · M. Sitnov · J.R. Hayes · L.E. Brown · R.S. Gurnee · J.C. Hutcheson · K.S. Nelson ·

C.M. Hammock · N. Paschalidis · E. Rossano $\cdot$ S. Kerem

Space Department, The Johns Hopkins University Applied Physics Laboratory, Laurel, MD 20723,

USA

L.J. Lanzerotti · K. Keika

Center for Solar Terrestrial Research, Department of Physics, New Jersey Institute of Technology,

Newark, NJ 07102, USA

J.W. Manweiler $(\bowtie)$

Fundamental Technologies LLC, Lawrence, KS 66046, USA

e-mail: Manweiler@ftecs.com 